\title{
METAPHYSICA DE ENTE REALI
}

\author{
Lúcio Álvaro Marques *
}

Resumo: Analisamos o significado do termo filosofia colonial brasileira com o objetivo de identificar evidências do sentido do trabalho filosófico à luz da Segunda Escolástica ou "escolástica colonial" representada pelo ensino inaciano no século XVIII. Para isso, fá-lo-emos através da análise das Conclusiones Metaphysicas de Ente Reali de Francisco de Faria (1747) com o fim de responder à pergunta: a tese de Faria representa os "sintomas de um pensamento decadente, incapaz de manter a pureza da ortodoxia" ou goza de certa originalidade filosófica?

Palavras-chave: Filosofia colonial brasileira. Duns Scotus. Francisco de Faria. Ente real.

Abstract: We analyze the meaning of the term colonial Brazilian philosophy with the aim of identifying evidence of its validity in light of the second Scholastic or "colonial scholastic", represented by the Ignatian school in the 18th century. We will do this through the analysis of Francisco de Faria's Conclusiones Metaphysicas de Ente Reali (1747), with the intent to answer the question: Does the thesis represent the "symptoms of a decadent thinking, unable to maintain the purity of orthodoxy" or does it have a certain philosophical originality?

Keywords: Colonial Brazilian philosophy. Duns Scotus. Francisco de Faria. Real Being.

* Professor do Departamento de Filosofia e Ciências Sociais da Universidade Federal do Triângulo Mineiro (UFTM), Uberaba. Pós-doutorado em Filosofia Brasileira pela Universidade do Porto, Portugal (2015). Artigo recebido em 21/10/2015 e aprovado para publicação em 13/09/2016. 


\section{Introdução}

$\mathrm{Q}$ ual é o sentido da expressão filosofia colonial brasileira? Há tanto quem discorde do sentido dessa expressão acusando a falta de sentido do ensino filosófico colonial quanto há quem ateste sua existencia e valor naquele sistema de ensino. A começar pelo problema da instituição e do desenvolvimento acadêmico do ensino nos séculos XVI-XVIII, em geral, reconhecem-se duas possibilidades: por um lado, nega-se a relevância da instituição acadêmica e, consequentemente, de tudo o que se possa ter produzido no período ou, por outro, afirma-se o vigor e a dinâmica própria desse ensino. Quando a pergunta refere-se ao teor do ensino filosófico colonial, as respostas tornam-se, então, mais distintas. Por isso, discutimos aqui uma possível abordagem da questão e do valor do ensino filosófico nesse período à luz de uma tese que exemplifica aspectos desse ensino. Nossa intenção volta-se ao sentido desse ensino e à matriz filosófica da obra analisada. Essa pesquisa inscreve-se no quadro bem mais amplo do Projeto Scholastica Colonialis que investiga a "Filosofia Escolástica Barroca na América Latina durante o período colonial" e pontuamos a análise dentro dos limites do ensino filosófico no Brasil.

\section{Status quaestionis}

As Conclusiones Metaphysicas de Ente Reali, defendidas e ofertadas pelo estudante Francisco Fraga e presididas pelo professor Francisco de Faria (1708-1769) ambos da Companhia de Jesus, constituem um raro exemplo tanto do ensino no período colonial quanto do teor da filosofia praticada nos Colégios Inacianos antes do processo de expulsão dos jesuítas (1759) levado a cabo por Sebastião José de Carvalho e Melo (Conde de Oeiras e Marquês de Pombal / 1699-1782). O documento consta de uma dedicatória ao Comendador João Gonçalves Fraga (redigida por Francisco Fraga, seu parente e beneficiado pelo patrocínio de seus estudos) e de uma questão principal seguida de três conclusões. Porém, cumpre destacar a proibição formal da impressão de livros no Brasil segundo a Carta Régia de oito de junho de 1706, que ordenava o fechamento de uma tipografia aberta em Recife e o sequestro de toda a sua produção. Entretanto, o tipógrafo português Antonio Isidoro da Fonseca, transferindo-se para o Rio de Janeiro, abriu lá em 1746 uma gráfica que foi interditada pelo governo lusitano depois de poucos meses. Foi nela que foram publicadas as Conclusiones Metaphysicae, gravadas em seda, como uma das raríssimas obras impressas no Brasil antes de 1808. Não obstante, é possível inferir com considerável grau de probabilidade a filosofia subjacente às conclusões redigidas por Francisco de Faria. 
A considerar algumas leituras correntes sobre o ensino inaciano no período colonial, encontramos afirmações gerais que o identificam ao pensamento aristotélico-tomista de segunda geração sem maiores sinais de originalidade ${ }^{1}$. Quanto à tese propriamente dita, Margutti ${ }^{2}$ considera-a devedora de "uma posição predominantemente aristotélica", o que não seria um despropósito, visto que Aristóteles constituía o conteúdo básico, senão exclusivo, do ensino filosófico segundo o Ratio Studiorum ${ }^{3}$. Sabemos, porém, que Margutti apenas conjecturou essa possibilidade, visto que não analisou a tese propriamente dita. Não obstante, a tese mereceu também uma interpretação geral feita por Fernando Arruda Campos em Uma disputa escolástica no século XVIII, sendo a única interpretação integral do conteúdo da tese até então.

Fernando Arruda Campos destacou algumas balizas teóricas que supostamente enquadram a obra. Ele identifica uma série de distintas e incongruentes influências na tese de Francisco de Faria. O jesuíta seria herdeiro do pensamento de Tomás de Aquino, Anselmo de Cantuária e René Descartes:

Neste exercício escolástico, o autor da tese pretende provar que a existência atual faz parte do conceito metafísico de Deus. Para tal admite, não apenas o argumento tomista ex contingentia o qual, entretanto, não desenvolve, como ainda o célebre argumento a simultaneo de Santo Anselmo. Este aparece, na tese, revestido da forma que lhe deu Descartes: parte-se da idéia clara e manifesta do Ser soberano e perfeito para se chegar à afirmação da existência real de Deus. Afirma, assim, o autor colonial que a proposição Deus existe é por si mesma evidente (per se nota), parecendo desconhecer a célebre distinção tomista entre evidente em si mesma (nota quoad se) e evidente quanto a nós (nota quoad nos). Para Santo Tomás, com efeito, a proposição Deus existe é evidente em si mesma, não porém, com relação $a$ nós. ${ }^{4}$

Quanto à primeira consideração, não haveria inicialmente maiores objeções acerca das possíveis influências de Tomás de Aquino e de Anselmo de Cantuária, porque o pensamento colonial esteve largamente marcado pela herança medieval. Ademais, Tomás de Aquino sempre recebeu um destaque ímpar na pedagogia inaciana. Ao lado de Aristóteles na filosofia, o Aquinate consta como a referência teológica no Ratio ${ }^{5}$, subordinado, obviamente, à Escritura e ao Concílio Tridentino. Embora Anselmo não conste nomeadamente no Ratio, não causaria admiração sua influência tanto na filosofia quanto na teologia de jesuíta colonial, visto que Francisco de

\footnotetext{
${ }^{1}$ CERQUEIRA, L. A. Filosofia brasileira: ontogênese da consciência de si, Petrópolis, Vozes, 2002.

${ }^{2}$ MARGUTTI, P. História da filosofia do Brasil (1500-hoje): 1aa parte, São Paulo, Loyola, 2013, p. 310.

${ }^{3}$ FRANCA, L. O método pedagógico dos Jesuítas - o "Ratio Studiorum", Rio de Janeiro, Agir, 1952, p. 159-162.

${ }^{4}$ CAMPOS, F. A., “Uma disputa escolástica no século XVIII", Rev. Brasileira de Filosofia, XVII (1967), p. 203-204.

${ }^{5}$ FRANCA, L., o. c., p. 143.
} 
Faria era professor de Humanidades, Filosofia e Teologia nos Colégios do Rio e da Bahia. Porém, a influência de René Descartes não parece óbvia, porque até a edição do Index Librorum Prohibitorum de Pio $\mathrm{XII}^{6}$, toda a Opera Philosophica de René Descartes era vetada à leitura dos fiéis católicos. Ademais, consta no Ratio a advertência acerca dos dotes dos professores de filosofia que não deveriam ser afeitos às novidades do pensamento e, considerando a situação de Descartes no Index, seria pouco provável que o jesuíta lhe atribuísse grande estima. Não obstante a brevidade da tese, Campos ainda admite que, na sequência dessa tríplice influência, há outras heranças subjacentes ao escrito. Ele afirma: "com relação ao conceito de ser, assume o jesuíta colonial posição claramente escotista, afirmando a univocidade." ${ }^{8}$ Esse aspecto não parece problemático, visto que na primeira conclusão há, de fato, uma opção pelo conceito unívoco. Ainda assim, há outra herança subjacente ao pensamento do jesuíta colonial:

O autor afasta-se ainda do Angélico, na definição dos transcendentais. A verdade não é definida como "a adequação entre a inteligência e a coi$\mathrm{sa}^{\prime}$ ", mas como "a conformidade da coisa com a regra de existir ou com o Exemplar divino", patenteando-se aqui uma clara influência da linha agostiniana na Escolástica. ${ }^{9}$

A considerar o enquadramento teórico proposto por Campos, o jesuíta seria herdeiro do pensamento de Tomás de Aquino, Anselmo de Cantuária, René Descartes, Joannes Duns Scotus e Agostinho de Hipona. Se houvesse verdadeiramente todas essas influências, não seria difícil admitir que nenhuma tese, mesmo em nossos dias, com tais características, seria aprovada por nenhuma banca examinadora. Tal tese seria apenas uma reunião confusa de ideias díspares e incongruentes sob uma mistura pouco provável. Assim, o parecer final de Campos estaria provido de veracidade:

Este documento espelha, desta forma, as características da filosofia na Colônia, tal como era ensinada nos colégios dos jesuítas. Às doutrinas tomistas misturam-se concepções alheias ao pensamento do Angélico, de origem escolástica umas, outras, porém, inteiramente estranhas a ela. Percebe-se nele, de forma evidente, os sintomas de um pensamento decadente, incapaz de se manter na pureza da ortodoxia. ${ }^{10}$

Admitidas as interpretações precedentes, não haveria dificuldade de se reconhecer "os sintomas de um pensamento decadente, incapaz de se manter na pureza da ortodoxia." A interpretação de Campos parece coesa se não olharmos mais atentamente o sentido e o vigor do ensino colonial

\footnotetext{
${ }^{6}$ Pio XII. Index Librorum Prohibitorum, Vaticanae, Typis Polyglottis Vaticanis, 1940, p. 129-130.

${ }^{7}$ FRANCA, L., o. c., p. 123.

${ }^{8}$ CAMPOS, F. A., o. c., p. 204.

${ }^{9}$ CAMPOS, F. A., o. c., p. 204.

${ }^{10}$ CAMPOS, F. A., o. c., p. 204-205.
} 
inaciano. Cumpre destacar que no tempo em que a tese foi redigida e defendida, o Ratio estava em pleno vigor não apenas na colônia, mas em todos os colégios inacianos. Ele era, provavelmente, o método pedagógico mais elaborado teoricamente do período moderno. E, pela sua ampla vigência, teríamos que admitir um relaxamento do seu rigor pedagógico para corroborar a interpretação de F. A. Campos.

O ensino filosófico colonial foi considerado por muitos autores como uma espécie de mera propedêutica teológica e desprovido de toda originalidade. Lima Vaz, por exemplo, analisando o teor da tese do seu confrade no horizonte da filosofia na sociedade colonial é categórico ao identificar qual seria o interesse da tese para a história da filosofia no Brasil: "nenhum."11 Essa tese, como as demais presentes e equivalentes no México, Colômbia, Peru, Argentina e Venezuela, não poderiam ser indexadas a uma pretensa história da filosofia latino-americana. E essa postura foi endossada por I. Domingues:

E o resultado é claro: somando-se o argumento linguístico (precariedade do português) ao argumento histórico-geográfico (isolamento das províncias e fronteiras incertas), e acrescentando-lhes ainda o argumento político (o status de colônia e, contra ele, o projeto de nação dos inconfidentes mineiros, delimitado por Minas, no máximo com a inclusão de Rio e São Paulo) mais o demográfico (fragilidade e deficiência de escala), nem com muito favor poder-se-ia falar em filosofia brasileira no período colonial. Quando muito em filosofia feita no Brasil, e ainda assim rala e precária, como mostrou Pe. Vaz, ponto ao qual voltarei na sequência. ${ }^{12}$

Lima Vaz e Ivan Domingues não concedem cidadania ao trabalho filosófico desenvolvido no período colonial. Antes, destacam a impossibilidade de qualquer identificação de uma "filosofia brasileira no período colonial." Naturalmente, a originalidade de uma filosofia não se reduz à presença de uma tese filosófica nem se pode relacionar, imediatamente, o ensino filosófico colonial à realidade colonial sem algumas considerações. Porém, a considerar a postura de Campos, Vaz e Domingues, todo o ensino colonial não recobra nenhum valor ou relevância para a história do pensamento brasileiro ou latino-americano. Essa postura, entretanto, não convém ser generalizada sem considerações. O próprio Vaz afirma que "essas mesmas teses [referindo-se à tese de Francisco de Faria e outras similares], provavelmente, eram defendidas na mesma época nos Colégios Jesuítas de Viena ou de Praga."13 Essa afirmação indica uma questão curiosa, pois se a tese em questão gozava de contemporaneidade em relação às teses

\footnotetext{
${ }^{11}$ VAZ, H. C. L. "O problema da filosofia no Brasil", Síntese - Rev. de Filosofia, 30 (1984), p. $19-20$.

${ }^{12}$ DOMINGUES, I. "Filosofia no/do Brasil: os últimos cinquenta anos", Rev. Analytica, 17/2 (2013), p. 91-92.

${ }^{13}$ VAZ, H. C. L., o. c., p. 19-20.
} 
de outros Colégios Jesuítas, qual seria a razão de se pensar na defasagem do ensino colonial latino-americano? Por que o ensino no Novo Mundo não teria o mesmo sentido que o ensino praticado em Viena ou Praga?

Lima Vaz permite entrever a atualidade do ensino no Novo Mundo, embora isso não signifique que tal ensino esteja "direta e originalmente" ligado à realidade colonial. Essa, porém parece uma questão óbvia, pois mesmo em nossos dias, quando se faz uma tese de exegese ou comentário de um autor clássico, dificilmente, essa tese vincula-se diretamente à realidade nacional em que é feita. As teses, cujo modelo predominante são a exegese e o comentário, vinculam-se raramente ao pensamento de qualquer nação. Com isso estamos dizendo que não convém identificar a tese de Faria com um monumento de originalidade do pensamento filosófico genuinamente brasileiro, mas apenas que essa tese pode indicar algo, possivelmente, sobre o modo, o teor e a forma do fazer filosófico no período colonial. Se aplicássemos a mesma análise de originalidade às teses filosóficas (exegéticas ou comentários) desenvolvidas nos dois últimos séculos no Brasil, quantas poderiam ser consideradas originais?

Dessa forma, deslocamos o problema da avaliação da tese de Francisco de Faria para outro patamar. A saber, queremos explicitar mediante a sua análise a possibilidade de se encontrar nele um pensamento coeso e rigorosamente filosófico, porque, antes de falarmos da originalidade da filosofia colonial brasileira, precisamos avaliar o rigor e o teor acadêmico do ensino colonial brasileiro. Porque se há quem nega a consistência do ensino colonial, há também quem atesta o contrário. Nesse sentido, não basta um argumento de autoridade, mas como proverbialmente afirma Ricardo Timm de Souza, a filosofia (no caso, esse registro de história do pensamento) acontece na passagem do argumento de autoridade para a autoridade do argumento. Se o argumento de autoridade fosse suficiente, poderíamos simplesmente reclamar outras posturas e teríamos a questão resolvida, porque segundo Caio César Boschi:

Vê-se, portanto, que a despeito de não se configurar como universidade stricto sensu e de não absorver um alunado tão numeroso quanto o que se constata contemporaneamente nas instituições universitárias da América hispânica, o ensino superior foi uma efetiva realidade na paisagem educacional do Brasil Colônia. ${ }^{14}$

Nesse sentido, se apenas o ensino de nível universitário constitui um digno exemplar da alta cultura filosófica, então o ensino colonial brasileiro também gozaria da mesma dignidade. Sabe-se que o ensino colonial foi propugnado pela Igreja, visto que o Reino deixou-o a seu encargo. Ademais, a política régia acerca do ensino, do livro e da imprensa tenderia mais claramente

${ }^{14}$ BOSCHI, C. C. "A Universidade de Coimbra e a formação intelectual das elites mineiras coloniais", Rev. Estudos Históricos, 4/7 (1991), p. 101. 
à recusa que à sua autorização ${ }^{15}$. A despeito do parco reconhecimento do ensino colonial e dos embargos à criação da Universidade do Brasil na Bahia e do Curso de Medicina (teoria e prática de cirurgia e anatomia) em Minas Gerais nos séculos XVII-XVIII, o ensino da filosofia e teologia não parecem suscetíveis de uma avaliação superficial. Além de Boschi, Rubens Borba de Moraes também afirma que "como sabemos, a Companhia de Jesus instituiu na colônia um sistema completo de aprendizagem, do ensino fundamental ao nível universitário."16 Daí que, afirmar ou negar reconhecimento ao ensino filosófico colonial exige uma avaliação rigorosa de todos os documentos remanescentes que chegaram até nós. E, não é desprovido de sentido o juízo de Serafim Leite referente à situação do ensino colonial, embora depois de seis décadas a situação já mostra bons avanços: "a história da cultura escolar colonial ainda não está feita em bases científicas, o que vem a significar que ainda não se estudou nas suas fontes, dentro do ambiente e dos livros que foram veículos dela"17. Exatamente nesse sentido, inscrevemos a análise da tese de Francisco de Faria. Analisá-la-emos em dupla perspectiva: em primeiro lugar, avaliaremos a justeza da afirmação de Vaz reassumida por Domingues: “...nem com muito favor poder-se-ia falar em filosofia brasileira no período colonial", sem analisar aqui propriamente a originalidade da filosofia brasileira, mas considerando a relevância ou o teor filosófico da tese e, em segundo lugar, frente à conclusão de Campos: "percebe-se nele, de forma evidente, os sintomas de um pensamento decadente, incapaz de se manter na pureza da ortodoxia." Para tanto, apresentaremos uma tradução da tese e um comentário no desejo de identificar os pressupostos filosóficos subjacentes à mesma. Teoricamente, não apenas duvidamos do suposto pensamento decadente e heterodoxo, mas acreditamos na possibilidade de identificar um lastro teórico único e originalmente filosófico na tese de Faria $^{18}$ que, em hipótese, consideramos uma tese escotista.

\section{Uma metafísica escotista tupiniquim?}

A possibilidade de uma avaliação diferente do teor da tese depende da forma como a lemos, por isso apresentaremos uma tradução da questão

\footnotetext{
${ }^{15}$ Analisamos a questão do ensino, do livro e da imprensa, bem como apresentamos uma leitura bem mais ampla da situação da filosofia colonial brasileira e uma tradução integral da tese de Francisco de Faria, incluindo a dedicatória, em MARQUES, L. A. Philosophia Brasiliensis: história, conhecimento e metafísica no período colonial, Porto Alegre, FI, 2015.

${ }^{16}$ MORAES, R. B. Bibliographia Brasiliana. A bibliographical essay on rare books about Brazil published from 1504 to 1900 and works of Brazilian authors published abroad before the Independence of Brazil in 1822, volume I, Amsterdam - Rio de Janeiro, Colibris, 1958, p. 258.

${ }^{17}$ LEITE, S. História da Companhia de Jesus no Brasil, tomo VII, Séculos XVII-XVIII, Rio de Janeiro, Instituto Nacional do Livro, 1949, p. 224.

${ }^{18}$ FARIA, F. Conclusiones Metaphysicas de Ente Reali, Flumine Januarii, Secunda Typographia Antonii Isidorii da Fonseca, 1747.
} 
principal e das conclusões mediante um comentário de cada parte. Na tradução, priorizamos a forma mais próxima ao literal conservando e destacando, sempre que possível, as perguntas debatidas, onde se reconhece claramente o caráter didático subjacente à escrita. A tese de Faria inicia-se com uma breve questão, cujo "desenvolvimento" encontra-se nas conclusões:

QUAESTIO PRINCEPS: Utrum existentia actualis sit de conceptu metaphysico Deitatis? Affirmative.
Questão principal: A existência atual pertence ao conceito metafísico da Divindade? Afirmativo.

A compreensão do pensamento medieval e, consequentemente, sua retransmissão fora dos limites do Velho Mundo e, no caso, das instituições de ensino europeias passa, necessariamente, pela obra jesuíta e de outras congregações na difusão do pensamento na chamada Segunda Escolástica ou Escolástica Colonial. Entretanto, essa retransmissão não se reduziu à repetição de conhecimentos e manuais sem uma assimilação distintiva do ensino no Novo Mundo. A difusão contou, por um lado, com a evolução e aproximação às novas matrizes de pensamento que se difundiam na Europa e, por outro, com a manutenção e assimilação de certas tendências do pensamento medieval. A continuidade do pensamento medieval não foi mera reprodução, mas, por vezes, uma considerável reavaliação dos modelos medievais. Essa possível reavaliação necessita ser documentada e, de certa forma, estamos convictos que o pensamento expresso nas Conclusiones metaphysicas de ente reali representam uma possibilidade de recolocar o debate sobre o sentido e alcance do ensino colonial. Pontualmente, cremos possível uma análise considerável da filiação escotista desse escrito e consequente superação de possíveis análises um pouco parciais. A considerar a questão principal, podem-se admitir diversas possibilidades de filiação teórica da resposta. Porém, analisando-a à luz das conclusões, somos tentados a considerar a seguinte hipótese de cunho escotista: em momento algum restringe-se a possibilidade do ser divino gozar de existência atual, porque "não é incompatível com o finito que haja algo mais perfeito", podendo o finito decorrer da existência do infinito ou a existência atual, da Divindade, e Duns Scotus afirma também: "a infinidade não repugna ao ser"19. Nesse caso, evitam-se críticas desnecessárias como se a condição divina não fosse compatível com a existência. Ao contrário, a questão atesta a perfeita compatibilidade entre divindade e existência atual. Analisemos, pois, a primeira conclusão:

${ }^{19}$ DUNS ESCOTO, J. Tratado do Primeiro Princípio, Lisboa, Ed. 70, 1998, IV, 9, p. 78-79. 
CO CLUSIO PRIMA. De Ente Reali in communi. Nobilissimum Metaphysicae objetum in agonem adducimus. Explicari solet id quod potest realiter existere. An vero dari, possit conceptus Entis perfecte praecissus ab omnibus suis inferioribus? Affirmamus. Ex quo sequitur praedictum Entis conceptum esse univocum ad inferiora. Contentiosse disputatur hic: utrum formalis ratio Entis transcendat formaliter differentias? Vera est resolutio affirmativa. Ens Reale ita consideratum tres potissimum proprietates habet, Unitatem, Veritatem, ac Bonitatem. Est autem Unitas Indivisio rei a se: hanc in positivo constituimus. Veritas transcendens apte dicitur: Conformitas rei cum regula essendi, sive Exemplari Divino. Bonitas tandem recte expenditur: Perfectio rei intrinseca, sive essentialis integritas praedicatorum. Quaeres: Utrum detur in rebus Falsitas, aut Malitia trascendens? Negative. Ens Reale adaequate dividitur in Divinum, et Creatum; in substantiam, et accdens. Divisio tamem in substantiam, et accidens est omnium prima, et principalior.
Primeira conclusão - Sobre o Ente Real em comum. Debatemos acerca do nobilíssimo objeto da Metafísica. Costuma ser definido como aquilo que pode realmente existir. Um conceito de Ente que prescinda perfeitamente de todos os seus inferiores é possível? Afirmativo. Donde se segue ser unívoco o conceito de Ente em relação aos seus inferiores. Discute-se obstinadamente a este respeito: se a razão formal de Ente transcende formalmente as diferenças? Verdadeira é a resposta afirmativa. O Ente Real, considerado desta maneira, tem principalmente três características próprias: Unidade, Verdade e Bondade. Por um lado, a Unidade é a Indivisão da coisa em si mesma: consideramos esta indivisão algo positivo. A Verdade transcendente é definida acertadamente como conformidade da coisa com a norma do ser ou com o Exemplar Divino. A Bondade, por fim, é tida justamente como: a perfeição intrínseca da coisa ou a essencial integridade de seus predicados. Inquire-se: há Falsidade ou Maldade transcendente nas coisas? Negativo. O Ente Real, adequadamente se divide em Divino e Criado; em substância e acidente. Todavia, a divisão em substância e acidente é a primeira e principal entre todas.

Tanto na primeira quanto nas outras conclusões ocorrem erros tipográficos e transcrevemos o texto latino com eles, corrigindo-os apenas na tradução. Conservamos também os itálicos inseridos no original. E, para iniciar as nossas considerações, o título da primeira conclusão opta por um conceito elucidativo - de ente reali in communi. A opção pela tradução ente evita o inconveniente do infinito do verbo sum - o esse. Não sendo a forma presente, não cremos conveniente adotá-la na tradução. Quanto ao conteúdo, a conclusão apresenta como objeto da metafísica o conceito de ente, enquanto abstrai perfeitamente de todas as diferenças e por isso é um conceito unívoco; acrescenta a definição dos transcendentes conversíveis com o ente (e dos "falsos" transcendentes) e introduz a divisão entre o divino e o criado, a substância e o acidente.

$\mathrm{O}$ ente, enquanto objeto da metafísica, define-se como aquilo que pode realmente existir. Tanto no plano dos entes finitos quanto do ente infinito, a possibilidade de existência configura o objeto da metafísica, bem como exclui outras realidades não conversíveis com o ente, ou seja, a falsidade 
ou a maldade transcendentes. Nega-se a possibilidade da transcendência da falsidade e da maldade, porque sua afirmação implicaria o reconhecimento de defeitos inerentes ao ente, o que já está negado pela afirmação da conversibilidade entre o ente e os três transcendentes anteriores. Aquilo que pode realmente existir distingue-se em dois aspectos: o que pode existir, mas que não existe necessariamente, e o que pode existir e, em virtude dessa possibilidade, existe necessariamente. Aquilo que pode realmente existir, mas que não é necessário, depende de outro que o torne atual, pois ele não se atualiza em virtude de sua própria possibilidade. Quanto àquilo que pode realmente existir e que existe necessariamente - esse é o ente superior. A distinção entre essas formas de possibilidade deve-se ao fato de que "a essência divina é formalmente a sua existência [...] no mesmo sentido, em que sua simplicidade intrínseca implica sua essência existente (sicut essentia divina est formaliter sua existentia [...] simpliciter ponitur gradus intrinsecus essentiae existentis) ${ }^{\prime 20}$. Especificado o objeto da metafísica - tanto o ente divino quanto os entes inferiores, enquanto aquilo que pode realmente existir - nosso autor indica a univocidade do conceito de ente entre o superior e os inferiores. A opção pela univocidade não é desconsiderável, pois a tradição que une Henrique de Gand e Tomás de Aquino e os defensores da analogia parece muito mais viva, inclusive na secunda escolástica, que a tradição da univocidade. Entretanto, a opção pela univocidade indica, claramente, um aspecto fundamental da herança filosófica do jesuíta, porque a univocidade constitui um dos núcleos teóricos da metafísica escotista. A decisão de empregá-la, revela, então, uma posição teórica claramente delimitada, pois se Faria estivesse apenas compendiando tradições aleatoriamente seria provável, então, que mencionasse a analogia, porém não é o caso. Além disso, todas as conclusões são coesas com o conceito de univocidade indicado na primeira conclusão. Por isso, pode-se reconhecer a relação com o conceito escotista:

Denomino conceito unívoco aquele que é uno, porque deste sua unidade suporta a contradição, afirmando e negando o mesmo a seu respeito; também [aquele que] suporta o mesmo enquanto termo médio silogístico, unidos os extremos pelo termo médio, conclui, deste modo, sem unir entre si a falácia de equivocação. (Univocum conceptum dico, qui ita est unus quod eius unitas sufficit ad contradictionem, affirmando et negando ipsum de eodem; [qui] sufficit etiam pro medio syllogistico, ut extrema unita in medio sic uno sine fallacia aequivocationis concludantur inter se uniri. $)^{21}$

Duns Scotus atribui à univocidade a possibilidade de identificação entre os conceitos absolutamente simples, enquanto aquilo que determina e

\footnotetext{
${ }^{20}$ DUNS SCOTUS, J. Quaestiones Quodlibetales, en Opera Omnia XII, Hildesheim, G. O. Verlag, 1969, VI, 13.

${ }^{21}$ DUNS SCOTUS, J. Ordinatio, en Opera Omnia. III/1, Italy, AGA, I, 3, 1, 2, 41.
} 
denomina algo, incluindo até a possibilidade da contradição. Por sua vez, afirmada a univocidade, Faria passa a definição das características próprias dos transcendentes. Quanto à Unidade, ele afirma: a Unidade é a Indivisão da coisa em si mesma, por outro, a constituição positiva. Tal definição não parece outra coisa que o eco das seguintes palavras: "a unidade em si é real sem qualquer operação do intelecto [...], a unidade é a natureza segundo si mesma (unitas in se realis absque omni operatione intellectus [...] unitas est natura secundum se)"22. A unidade é, portanto, a constituição própria da coisa a partir de si mesma, excluída a unidade da singularidade material. Quanto à Verdade, afirma ser a conformidade da coisa com a norma do ser ou com o Exemplar Divino. Por essa definição já se reconhece a distância entre Faria e Isaac Israeli ben Solomon, cuja definição da verdade - adequatio rei et intellectus - foi assumida por Tomás de Aquino. Porém, a definição do jesuíta soa em uníssono com a seguinte definição: "[a verdade] é uma adequação do objeto à intelecção divina, porque a intelecção divina é una ([veritas] est adaequatio obiecti ad intellectionem divinnam, quia intellectio divina est una)"23. A adequação da verdade à intelecção divina ou à lei da entidade parece patente entre as duas formulações. Quanto à bondade - a perfeição intrínseca da coisa ou a essencial integridade dos seus predicados - o jesuíta também parece claro herdeiro escotista, porque a bondade "é a perfeição é a perfeição segunda de uma coisa integrada por todos os atributos que lhe convêm e que se convêm reciprocamente, bem como por todos os atributos que os completam (est perfectio secunda alicuius rei integrata ex omnibus convenientibus sibi et sibi invicem, et omnibus illis concurrentibus)" 24 . Novamente, não parece difícil reconhecer a proximidade entre eles e, tal qual, a negação da transcendência à Falsidade e à Maldade, também a encontramos em Duns Scotus. A Falsidade e Maldade existem apenas no modo da predicação (in praedicationis modo), como pecado expresso na injustiça atual ou habitual (iniustitia actualis vel habitualis), como privação de bem conveniente por natureza (privat aliquid conveniens illi naturae) e como privação de um bem moral por carência de ciência ou de virtude (ut scientiam aut virtutem) ${ }^{25}$. Finalmente, a distinção entre o ente divino e o criado, a substância e o acidente também consta em ambos, porém a partir do conceito unívoco de ente. Assim sendo, nossa hipótese parece plausível quanto à primeira conclusão, por isso passemos à análise da segunda:

${ }^{22}$ DUNS SCOTUS, J., o. c., II, 3, 1, 30.

${ }^{23}$ DUNS SOCTUS, J. Collationes Parisiensis et Oxoniensis, en Opera Omnia II/1, Italy, AGA, 1998, 19, 6, 24.

${ }^{24}$ DUNS SCOTUS, J. Ordinatio, o. c., II, 40, q. un., 6.

${ }^{25}$ DUNS SCOTUS, J. Quaestiones super librum Perihermeneias, en Opera Omnia I, Italy, AGA, 1998, 7, 2; Reportata Parisiensia, en Opera Omnia II/2, Italy, AGA, 1999, II, 42, 4, 16; Lectura, en Opera Omnia II/1, Italy, AGA, II, 34-37, 4, 160. 
CONCLUSIO SECUNDA. De Ente Divino. Ens Divinum, quantum naturalis ratio patitur, non immerito contemplantur Philosophi. Decernimus 1. Existentiam Dei esse naturaliter demonstrabilem a posteriori, ut contra Atheorum insaniam quaevis creatura testatur. Decernimus 2. Non a posteriori tantum, sed quase a priori praedictam existentiam demostrari posse per Ideam Entis Optimi, aut summe Perfecti. Quare singulariter volumus 1. Extare nobis Ideam Entis summe Perfecti: volumus. 2. Propositionem istam Deus existit esse per se notam. Quaeres:

quid sit Deus? Respondetur Essentia Dei Metaphysice considerati est Ens a se. Ex quo sequitur 1. Praedictam essentiam non consistere in aggregato omnium attributorum. Sequitur 2. Non consistere in Intellectivo radicali, sive Rationali Divino. 3. Neque in Intellectivo potentiali, aut actuali Intellectione. 4. Non constitui per Infinitatem: sola enim Asseitas est formale constitutioum Divinae Essentiae. Si vero loquamur in sensu physico, Essentia Divina Theologice sumpta constituitur ex solis praedicatis absolutis: sumpta vero Philosophice ex absolutis simul, et relativis; subindeque ex adaequato confluxu Divinarum perfectionum.
Segunda conclusão - Sobre o Ente Divino. Não sem mérito, refletem os Filósofos sobre o Ente divino quanto é acessível à razão natural. Pensamos: 1 . Que a existência de Deus é demonstrável a posteriori pela razão natural, contra a loucura dos Ateus, como testemunha qualquer criatura. Pensamos: 2. Que a predita existência pode ser demonstrada não somente a posteriori, mas também de algum modo a priori pela noção de Ente Excelente ou sumamente Perfeito. Por isso, sustentamos particularmente: 1 . Que há em nós a noção do Ente sumamente perfeito. 2. Que esta proposição Deus existe é conhecida por si mesma. Inquire-se: o que seja Deus? Responde-se: a Essência de Deus metafisicamente considerada é Ente a partir de si. Daí se segue: 1. Que a predita essência não consiste no agregado de todos os seus atributos. 2. Que ela não consiste em uma Inteligência radical ou em uma Racionalidade Divina. 3. Nem em uma Inteligência potencial ou em uma Intelecção atual. 4. Nem se constitui pela Infinitude: pois, na realidade, apenas a Asseidade é o constitutivo formal da Divina Essência. Se, porém, falamos em sentido físico, a Essência Divina, tomada teologicamente, constitui-se, unicamente por seus predicados absolutos, e, tomada filosoficamente, por seus predicados absolutos e relativos, simultaneamente; e, consequentemente, pela adequada convergência das perfeições Divinas.

A segunda conclusão apresenta um dos aspectos mais interessantes da tese de Francisco de Faria, porque situa a possibilidade de compreensão demonstrativa do ente divino e apresenta duas definições formais do mesmo. Porém, antes de passarmos à consideração do conteúdo, necessárias se fazem algumas correções quanto à tradução de Fernando Arruda Campos. Na sua tradução há quatro elementos problemáticos: o primeiro encontra-se na tradução de "non a posteriori tantum, sed quase a priori..." a palavra tantum seguida da adversativa sed indica uma frase subordinada adversativa comparativa no sentido de "não apenas..., mas também...". O problema encontra-se no fato de ele ter traduzido ou mantido o termo "quase" (que deveria ser grafado como quasi, por óbvio, um erro tipográfico) no sentido que tem em português, quando no texto latino significa "de algum modo". Isso é notório pelo fato da expressão empregada por ele - 
"quase a priori" - não ter um sentido preciso na frase "que tal existência pode ser demonstrada não apenas a posteriori mas ainda quase a priori pela...", quando na verdade, a expressão pode ser claramente entendida considerando-a uma frase subordinada adversativa: "não somente a posterio$r i$, mas pode-se demonstrar a priori, do mesmo modo, a predita existência pela..." Estamos diante de um exemplo clássico da discussão metafísica a interrogar-se sobre a possibilidade das demonstrações a posteriori e a priori da existência divina. Essa tese proposta em 1747 antecipa uma resposta à célebre questão da Crítica da Razão Pura de Kant (1781) que interroga, exatamente, a possibilidade dos juízos sintéticos a priori na metafísica, tais como ocorrem na matemática e na física. O segundo elemento encontra-se na transcrição do termo que inicia a próxima frase: "Quase singulariter volumus", traduzido por "Estabelecemos, pois, distintamente", quando, na verdade, a frase começa com "Quare singulariter volumus", que traduzimos como: "Por isso, sustentamos singularmente." A diferença entre os termos indica não uma frase explicativa - quase traduzido como pois, mas uma frase consecutiva - quare traduzido como por isso. O terceiro elemento é, verdadeiramente, grave, porque no texto transcrito por Campos lemos: "Quase singulariter volumus 2. propositionem istam...", porque ele omite deliberada ou equivocamente um período, sendo o texto completo o seguinte: "Quare singulariter volumus 1. extare nobis Ideam Entis summe Perfecti: volumus. 2. propositionem istam..." Finalmente, na tradução da resposta à questão - o que seja Deus? - ele insere a palavra asseidade na tradução em lugar de Ens a se. Tanto a expressão Ens a se quanto asseidade são termos técnicos não livremente intercambiáveis, porque comportam sentidos precisos e o termo asseitas consta adiante na mesma resposta, o que não permite simplesmente inseri-la a bel prazer do tradutor, sem uma justificativa prévia. Afinal, há questões de estilo que provocam diferenças nas traduções, além do desejo de mantermos uma tradução o mais próxima possível do literal, quando os termos o permitem, o que também não exclui proximidades com a tradução proposta por Campos.

Estabelecidas essas ressalvas, cumpre pontuar a possibilidade da demonstração a posterior e a priori do Ente Divino pela luz da razão natural. Com isso, Faria delimita exatamente o aspecto em que se deve entender sua tese, além de pontuar no final da conclusão a distinção entre a compreensão da essência divina na teologia e na filosofia. A opção pela razão natural, sem o auxílio da iluminação divina, revela o rigor da busca filosófica empreendida na tese, cuja primeira afirmação referente ao Ente Divino identifica-o pela noção de Ente Excelente ou sumamente Perfeito, com as mesmas palavras de Duns Scotus: "Deus é sumamente perfeito (Deus est maxime perfectus)" 26 ou ainda em equivalência ente eminentíssimo destacado nas demonstrações da existência divina no Tratado do Primeiro Princípio e

${ }^{26}$ DUNS SCOTUS, J. Reportata Parisiensia, o. c., II, 44, q. un., 14. 
no comentário de um autor recente, Prentice ${ }^{27}$. A isso segue a afirmação da evidência da proposição Deus existe. Quanto a esse ponto, Campos pensa encontrar aqui a reelaboração cartesiana do argumento anselmiano; porém mediante uma leitura mais atenta das obras escotistas pode-se reconhecer a influência anselmiana, mas assumida pelo próprio Duns Scotus: "Aquele que não é, de forma alguma finito, logo é infinito (Illud etiam non est aliquod finitum, ergo infinitum), é o mesmo que se reconhece pela evidência afirmativa - "tal é aquela [afirmação] 'Deus é/existe' (qualis est illa 'Deus est')" 28 . A formulação escotista cita Anselmo, porém inferir que tal formulação seria cartesiana, parece pouco provável. A evidência do conhecimento de Deus no pensamento medieval não é da mesma ordem que no sistema cartesiano. Quando os medievais afirmam tal evidência, fazem-no em virtude da primazia divina em relação aos demais entes, porque “Deus é o primeiro cognoscível, por esse motivo é perfeitíssimo, o que concedo, embora não o primeiro adequado [ao conhecimento]. (Deus est primum cognitum, hoc est perfectissimum, quod concedo, sed nom primum adaequatum)" ${ }^{29}$. Chegado a esse ponto, Faria explicita a questão: quid sit Deus?

À questão segue-se uma resposta inequívoca: "a Essência de Deus metafisicamente considerada é Ente a partir de si." Fizemos questão dessa tradução porque a expressão Ente a si não comporta a mesma carga semântica da outra. Dizer que Deus é Ente a partir de si evidencia duas distinções fundamentais em relação aos outros entes que são sempre a partir de outro e são meramente possíveis, enquanto a possibilidade $a$ partir de si mesmo implica sua necessidade, porque "a possibilidade em Deus impõe a necessidade de sua existência (Possibilitas in divinis ponit necessitatem $)^{\prime \prime 30}$. Posta a primeira definição, segue-se a tripla negação: a essência divina não consiste em um agregado de atributos, nem uma intelecção radical ou um divino racional, nem uma pura intelecção potencial ou atual, porque "na realidade, apenas a Asseidade é o constitutivo formal da Divina Essência." Tal qual o conceito de univocidade, o conceito asseidade (haecceitas ou asseitas) revela outra proximidade teórica de enorme relevo.

Há quem aponte o synolon aristotélico como o conceito inspirador da asseidade, além das supostas heranças presentes na "escola de Oxford" (Thomas de York, Roger Bacon e John Pecham). Entretanto, o inconveniente do conceito synolon encontra-se no fato de ele ser entendido aristotelicamente como o "elemento concreto ou composto de matéria e forma" ${ }^{31}$, enquanto o

\footnotetext{
27 PRENTICE, P. The basic quidditative metaphysics of Duns Scotus as seen in his De primo principio, Roma, PAA, 1997, p. 180.

${ }_{28}^{28}$ DUNS SCOTUS, J. Ordinatio, o. c., I, 2, 1, 2, 11 e 13.

${ }^{29}$ DUNS SCOTUS, J. Ordinatio, o. c., I, 3, 1, 2, 151.

${ }^{30}$ DUNS SCOTUS, J. Quaestiones Quodlibetales, o. c., II, 54.

${ }^{31}$ ARISTÓTELES. Metafísica, volume II, São Paulo, Loyola, 2002, 8, 1033 b19.
} 
conceito medieval de asseidade rejeita a composição hilemórfica. A asseidade constitui a característica específica que faculta a identificação individual sem o concurso da diferença última, ela é, propriamente, o "princípio de individuação (principium individuationis)" ou aquilo que permite a distinção entre os entes, o que caracteriza um ente sem recurso à diferença última ${ }^{32}$. A asseidade, tal como a univocidade, ganha expressão no pensamento medieval, sobretudo, com Duns Scotus:

Aquilo que convém em qualquer parte por sua própria razão, convém por si mesmo em toda condição, na qual é a mesma coisa; pois se a substância material é assim por si mesma, e independente de onde esteja, desse modo, nela estaria a haecceitas. (Quod convenit alicui ex sua ratione, sibi convenit in quolibet, in quo ipsum est; igitur si substantia materialis ex se esse hoc, in quocumque esset, in eodem esset illa haecceitas. $)^{33}$

Sendo a asseidade a "última atualidade da forma (ultima actualitas formae)" e aquilo que a especifica, precisamente, o que convêm de modo próprio e faz com que algo possa ser identificado exatamente e sem nenhuma confusão, cremos que a asseidade aplica-se propriamente à constituição da Essência Divina. Assim sendo, a asseidade divina pode ser entendida a partir daquilo que afirmou o jesuíta, ou seja, essa asseidade ou Essência divina seria o Ente excelente ou sumamente perfeito, o Ente a partir de si e aquele acerca do qual pode-se dizer - Deus existe - e cuja existência pode ser demonstrada de modo a posteriori e a priori pela razão natural. Faria acrescenta ainda a distinção entre a compreensão teológica (a partir dos predicados absolutos) e filosófica (a partir dos predicados absolutos e relativos) da Essência divina. Na compreensão escotista, processa-se algo semelhante, pois à infinitude agregam-se todos os outros conceitos sabedoria, amor, onipotência, etc. - embora reconheça-se a proeminência do conceito infinitude ${ }^{34}$. Os transcendentes - unidade, verdade e bondade - conhecidos e tematizados no Medievo a partir da Suma de bono de Filipe, o Chanceler, da Suma Theologica fratis Alexandri e do comentário ao primeiro livro das Sentenças e o De Veritate de Tomás de Aquino, constituem os predicados fundamentais da divindade. Para Duns Scotus, não obstante a proeminência da infinitude, compreende-se a Essência divina a partir de todos os conceitos (sabedoria, amor, onipotência, etc.), de modo que, essa afirmação não parece estranha ao jesuíta, porque ele pensa a Essência transcendente mediante a adequada convergência das perfeições divinas. Agora, porém, consideremos a terceira conclusão:

${ }^{32}$ DUNS SOCTUS, J. Collationes Parisiensis et Oxoniensis, o. c., 25, 2, 9-10.

${ }^{33}$ DUNS SCOTUS, J. Reportata Parisiensia, o. c., II, 12, 5, 152.

${ }^{34}$ DUNS SCOTUS, J. Ordinatio, o. c., I, 2, 1, 2, 67. 
CONCLUSIO TERTIA. De Ente Creato. Ens creatum, ut a Divino condistinctum, aut est actuale, aut Possibile. Circa possibilitatem creaturarum nodose disceptatur : quid sit ab aeterno, et ante omnem existentiam? In quam rem dicimus 1. Possibilitas creaturae non consistit in aliquo esse actuali, et absoluto actualitate essentiae a Deo distincto. Dicimus 2. Non consistit in aliquo esse diminuto, vel negativo. Dicimus 3. Non consistit in esse conditionato praeter Deum. Nullam igitur possibilitatem agnoscimus distinctam a praedicatis Divinis: quocum Divina Onipotentia, Divinisque Ideis omnem omninino possibilitatem creatam identificamos. Ens actuale constituitur tale per existenciam. Si petas utrum existentia distinguatur realiter ab essentia creata? Affirmamus. Superest, ut opposita entis realis expendamus. Datur ne Impossibile primo intentionaliter contradistinctum ab omni possibili? Negative. Et quid de Ente rationis, sive Impossibili secundo intentionaliter? Erit ne aliquid a possibilibus diversum? Negative. Ens rationis impossibile nihil est praeter objecta realia sinistre identificata per actum falsum. Non datur similiter Ens negativum ab omni positivo contradistinctum; atque adeo formales rerum carentiae nihil sunt.
Terceira conclusão - Sobre o Ente Criado. O Ente criado, enquanto codistinto do divino, é atual ou possível. Intensamente se debate acerca da possibilidade das criaturas: o que há desde a eternidade e anterior a toda existência? Quanto a essa questão, afirmamos: 1. A possibilidade da criatura não consiste em um ser atual e absoluto, distinto de Deus pela atualidade da essência. 2. Não consiste em um ser minúsculo ou negativo. 3. Não consiste em ser condicionado, além de [distinto de] Deus. Por conseguinte, não reconhecemos nenhuma possibilidade distinta dos predicados Divinos: identificamos toda e qualquer possibilidade criada com a Onipotência e as Ideias Divinas. O Ente atual constitui-se como tal pela existência. Se perguntares se a existência se distingue realmente da essência criada? Afirmamos. Resta ainda que discorramos acerca dos opostos aos entes reais. Admite-se o Impossível, intencionalmente primeiro, contradistinto a todo [ente] possível? Negativo. E o que dizer sobre o Ente de razão ou o Impossível intencionalmente segundo? Não será algo diverso de todo possível? Negativo. O Ente de razão impossível não é senão um objeto real mal identificado por um ato falso. Do mesmo modo, não se admite o Ente negativo como contradistinto a todo [Ente] positivo; e também as carências formais das coisas nada são.

Após tratar do Ente real em comum e do Ente divino, Francisco de Faria trata o Ente criado segundo sua possibilidade e frente ao negativo. A terceira conclusão assemelha-se, largamente, a uma glosa do pensamento escotista. Tanto Francisco de Faria quanto Orlando Todisco em obra recente sobre Scotus parecem simplesmente glosar uma passagem da Ordinatio $^{35}$. Todisco destaca a dependência e a radical contingência do ente criado em relação ao ente divino, a existência do criado em virtude da possibilidade, a inteligibilidade inerente ao ente, o conhecimento do divino a partir das interrogações do criado, a não-contraditoriedade ou a impossibilidade do impossível e do negativo enquanto entes e a finitude como uma condição de ausência de carências ou isenta de caducidade

${ }^{35}$ DUNS SCOTUS, J. Ordinatio, o. c., I, 2, 1, 2, 45 e 56. 
pela sua relação com o divino ${ }^{36}$. Todos esses temas são, de certa forma, comuns a Faria e Todisco.

Francisco de Faria situou o ente criado entre o atual e o possível e identificou a possibilidade como a não recusa em relação ao necessário; e, quanto à atualidade, identificou-a à ausência de privação e ao condicionamento exclusivo ao necessário. Resta-nos, portanto, averiguar se o emprego desses conceitos pelo jesuíta é coerente com o sentido dado aos mesmos por Duns Scotus. Inicialmente, reconhece-se em Duns Scotus, a compreensão da atualidade (actualitas) enquanto condição isenta de "privação e carência material (privatio et carentiae materiae)", ela relaciona-se com o ente criado como sua "paixão natural (passio suae naturae)" 37 , porque distingue-o da ideia divina mediante a qual o ente passa da possibilidade à atualidade. A ideia divina que faculta a atualização do ente somente o faz por atuação do necessário (necessarium). Esse é entendido como o imediato e sem mudança, aquele que não depende de outro para ser, o que "em si deve conter a necessidade intrínseca (necessarium ex se debet intrinsece habere necessitatem)" ${ }^{\prime 38}$, entendendo por necessidade (necessitas) o que não depende de outro para existir (quod non contingit aliter se habere) ${ }^{39}$. Por sua vez, o franciscano define o possível como "o comum quanto ao ente em ato ou ao ente segundo o ser da sua essência (communius quam ens in actu vel ens secundum esse essentiae)" 40 . Entende-se o possível segundo duplo aspecto, pois ele é a atualização do ente ou o ente segundo sua própria essência. Enquanto atualização do ente entende-se a passagem da possibilidade à atualidade mediante a ação do necessário, e enquanto possível segundo a própria essência, entende-se aquele que é possível, cuja possibilidade, implica sua necessidade ou, ainda, de forma mais explícita: "[Entende-se, portanto, como] possível o que é o próprio objeto da potência ativa, o possível é o que se opõe ao "ser necessário por si", o que tem o ser por outro e é por si possível (Possibile igitur quod est proprium obiectum potentiae activae, est possibile quod opponitur "necesse esse ex se", quod est habens esse $a b$ alio et de se possibile $)^{41}$. Nesse sentido, podemos admitir que o jesuíta

${ }^{36}$ TODISCO, O. Lo spirito cristiano della filosofia di Giovanni Duns Scoto, Roma, Abete, 1975, p. 201-211.

${ }^{37}$ DUNS SCOTUS, J. Reportata Parisiensia, o. c., I, 35, 1, 22.

${ }^{38}$ DUNS SCOTUS, J. Quaestiones subtillissimae super libros Metaphysicorum Aristotelis, en Opera Omnia I, Italy, AGA, 1998, V, 3, 28.

${ }^{39}$ DUNS SCOTUS, J. Lectura, o. c., I, 39, 5, 77.

${ }^{40}$ DUNS SCOTUS, J. Lectura, o. c., I, 36, q. un., 36.

${ }^{41}$ DUNS SCOTUS, J. Lectura, o. c., I, 20, q. un., 21. O conceito possibilidade assume no pensamento escotista uma tríplice acepção, segundo TODISCO, O., Lo Spirito..., o. c., pp. 108-109: pensa-se o possível como ente contingente que significa a possibilidade e a indiferença quanto a ser e a não ser, porque o ente contingente não implica nenhuma necessidade de existir a fortiori; o possível lógico como objeto do intelecto divino, mas que não implica a efetiva necessidade da onipotência que o faça vir a existir; o possível metafísico como o que pode ser atualizado através da causa intrínseca, mas que também não tem necessidade absoluta de existir, porém é aquele cuja essência projeta-se na existência. 
empregou, mais uma vez, com elevado grau de verossimilhança, os conceitos do franciscano. Não diferindo do visto nas conclusões precedentes. Com isso, reconhecemos que o ente criado no pensamento de Francisco de Faria foi enquadrado teoricamente no mesmo universo conceitual de Duns Scotus, o que evidencia, de certa forma, a nossa hipótese. E, após situar a condição do ente criado, o nosso autor apresenta uma das raras definições cabais presentes na tese: "o Ente atual, enquanto tal, constitui-se pela existência (Ens actuale constituitur tale per existentiam.)" Considerando a autoridade de Avicena, Duns Scotus identifica o ente, por um lado, como primeiro (primum), a saber: a substância, no sentido daquilo que é subsistente e que permanece (subsistendi et substandi) e, "por outro, o ente impõe-se como o ato existente ("ens" autem imponitur ab actu essendi.)"42. Naturalmente, essa não é uma afirmação em primeira mão do franciscano, porém, na Ordinatio, não restam dúvidas, porque atribui-se ao ente existente (ens existens) a primazia frente à eficiência, o fim e a eminência, além de atestar a primazia do ente, enquanto a "entidade existente em ato (entibus exsistit in actu)", do mesmo modo que pode falar do ente infinito como "ente existente em ato (ens existit in actu)" "43. A constituição da atualidade do ente mediante a existência não difere, novamente, do pensamento do autor medieval, para quem a atualidade efetiva-se na existência em ato. Sendo assim, eis mais um ponto de contato entre os autores.

A segunda parte da conclusão inicia com a distinção entre existência e essência criada e a resposta é inequívoca: afirma-se a distinção, obviamente, porque admite-se a coincidência entre essência e existência apenas com relação a Deus. Quanto a todos os entes criados, a essência não pressupõe a existência, porque sua existência é apenas possível, mas não necessária, ao contrário, em Deus ou no ente necessário, a essência implica sua existência: "em Deus", afirma o franciscano, "a essência compreende a existência atual... (in Deo [...] essentia accipitur pro existentia actuali...)" e um pouco mais adiante nas Quodlibetales, o autor reafirma sua tese: "a possibilidade em Deus impõe a necessidade de sua existência (Possibilitas in divinis ponit necessitatem) ${ }^{\prime \prime 4}$. Depois de apresentar e responder à questão, o jesuíta passa à discussão sobre os opostos aos entes reais. Os enunciados referidos como opostos aos entes reais englobam o impossível (intencionalmente primeiro), o ente de razão (intencionalmente segundo), o ato falso, o ente negativo e as carências formais nos entes. E categoricamente o jesuíta nega-lhes a existência. Não há razão para se admitir em nenhuma forma qualquer uma dessas acepções como opostos aos entes reais. Uma existência negativa no sentido de algo oposto ao ente é uma contradição no pensamento de Francisco de Faria, bem como no pensamento de Duns Scotus. A conversibilidade entre o ente e os transcendentes faculta uma visão, essencialmente, positiva de todo ente.

\footnotetext{
${ }^{42}$ DUNS SCOTUS, J. Quaestiones super Praedicamenta, en Opera Omnia. I, Italy, AGA, 1998, 4, 59.

${ }^{43}$ DUNS SCOTUS, J. Ordinatio, o. c., I, 2, 1, 2, 183 e 185.

${ }^{44}$ DUNS SCOTUS, J. Quaestiones Quodlibetales, o. c., I, 7 e II, 54.
} 
A negação de todas as possibilidades ao impossível (primeiro ou intencional segundo), ao falso, ao negativo e às carências formais justificam-se mediante a compreensão da herança escotista que perpassa nosso autor. Consideremos brevemente cada aspecto comentando os termos empregados por Faria através das definições escotistas dos mesmos: compreende-se o impossível intencionalmente primeiro como aquilo cuja existência não implica necessidade e cuja singularidade específica não se sustenta, porque, como impossível, nega-se sua razão formal de ser (...aut non necesse est singularitatem specie ostendi, quia nec esse rationem formalem cognitionis cuiuscunque...); quanto ao impossível intencionalmente segundo ou o ente de razão, pensá-lo já constitui uma contradição em termos, pois o impossível não existe sequer como um ato de razão, porque a própria intelecção do impossível significa a negação da sua possibilidade, ainda que apenas como ato de razão, visto que pensar o impossível como ente de razão implicaria em primeiro lugar criar uma intelecção inteligível do mesmo (Primum intelligibile intellectione creari, impossibile), logo sendo inteligível, já não pode ser impossível ${ }^{45}$. Por sua vez, o falso seria o concebido a partir de uma essência diversa ou diferente daquela que verdadeiramente o constitui, porque se for coerente com a própria essência, é verdadeiro, portanto, o falso indica algo impróprio em relação a um ente específico ou algo que não lhe é intrínseco, por isso não tem uma existência positiva ou, ainda, como já enunciamos, o falso não existe no acontecimento propriamente dito da coisa, mas no modo da predicação (in praedicationis modo ${ }^{46}$. O negativo seria a refutação do ente positivo, ou seja, simplesmente do ente, enquanto conversível com o bem. Não se pensa o negativo como o não-ente em oposição ao ente, nem ao menos como algo dotado de qualquer possibilidade real. Excluindo-se a possibilidade de conceber o negativo como não-ente, abre-se a possibilidade de pensar o mal no mundo. $\mathrm{O}$ mal também não possui uma existência real, segundo Duns Scotus. Por isso, a possibilidade de pensá-lo acontece apenas enquanto se concebe a possibilidade de Deus permiti-lo no mundo, embora essa permissão não signifique um desígnio divino. Nesse sentido, só se entende o mal ou o negativo em vistas de um fim divinamente disposto e que implica, de algum modo, a passagem por um ou outro aspecto quer seja o mal quer o negativo. Porém, há que se ressaltar que o mal ou o negativo não significam nem um erro nem um não-ente ${ }^{47}$. Finalmente, as carências formais que, segundo Francisco de Faria, não existem nas coisas (atque adeo formales rerum carentiae nihil sunt.) Todas as coisas existentes comportam em si mesmas toda a perfeição própria e conveniente. Não há nenhuma falta nas formas de onde se originam os entes. O que não impede o reconhecimento de defeitos presentes neles, porém um defeito não provem da causa que gera o ente nem de uma falta inerente à sua essência ou à sua

${ }^{45}$ DUNS SCOTUS, J. Theoremata, en Opera Omnia I, Italy, AGA, 1998, 3, 5 e 2, 2.

${ }^{46}$ DUNS SCOTUS, J. Ordinatio, o. c., II, 12, 1, 16 e Quaestiones super librum Perihermeneias, o. c., 7, 2.

${ }^{47}$ DUNS SCOTUS, J. Lectura, o. c., I, 2, 1,1-2, 60-63. 
forma, o defeito (defectus) decorre da ausência de uma perfeição devida proveniente de uma causa inferior segunda ${ }^{48}$. É nesse sentido que Francisco de Faria também afirma a ausência de carências formais, tal como Duns Scotus diz haver, por causa da atualidade (actualitas), a perfeição do ente em virtude de sua própria razão formal (sua ratione formali), visto que a atualidade do ente traz em si todas as perfeições possíveis que lhe são inerentes segundo sua forma. Não havendo, pois, nenhuma carência formal no ente. Todos os limites e imperfeições presentes em algum ente atual decorrem de uma causa segunda. Como afirma Duns Scotus ${ }^{49}$, as imperfeições decorrem necessariamente de uma "privação ou carência da matéria (quam consequitur privatio et carentia materiae)" ou, afirma Faria, "não existem carências formais nos entes (formales rerum carentiae nihil sunt)."

\section{Conclusão}

Apresentamos uma hipótese com dupla perspectiva: a primeira relativa à relevância ou ao teor filosófico da tese de Francisco de Faria. Frente ao texto da parte sistemática da tese (a quaestio princeps e as conclusões) cremos na possibilidade de se reconhecer a seriedade do ensino inaciano no período colonial. Com isso, estamos dizendo que não nos parece simples nem completamente aceitável a afirmação de que o ensino da filosofia no Brasil não goza de interesse antes da fundação das universidades. Embora estejamos diante de apenas um exemplo do ensino colonial, o seu caráter rigorosamente acadêmico não pode ser escusado. A tese do jesuíta colonial não nos parece apenas um exercício diletante, mas indica algo da vivacidade e do rigor do trabalho filosófico na colônia. Quanto ao valor desse único exemplar, esperamos no futuro encontrar outras teses e manuscritos dos quais já temos alguma informação e submetê-los-emos ao mesmo exame. Quanto à segunda perspectiva da nossa hipótese, pensamos que Fernando Arruda Campos fez uma leitura demasiado rápida do texto, inclusive com alguns limites na tradução que propôs e com parca atenção a outras possibilidades interpretativas. Por isso, admiramo-nos do seu parecer (um pensamento decadente, incapaz de se manter na pureza da ortodoxia) e, crendo outra possibilidade interpretativa, à medida que refizemos a leitura da tese, tornou-se, paulatinamente, mais evidente sua proximidade com o pensamento escotista. Se nossa hipótese goza de coesão, é necessário notar que o ensino inaciano não apenas primou pela escolástica aristotélico-tomista, mas viabilizou um horizonte teórico capaz de integrar e desenvolver uma leitura ampla e rigorosa inclusive do escotismo, para nos determos apenas na tese de Francisco de Faria.

\footnotetext{
${ }^{48}$ DUNS SCOTUS, J. Ordinatio, o. c., II, 37, 2, 112.

${ }^{49}$ DUNS SCOTUS, J. Reportata Parisiensia, o. c., I, 35, 1, 22.
} 


\section{Bibliografia}

ARISTÓTELES. Metafísica, volume II, texto grego, tradução e comentário de Giovanni Reale, tradução brasileira de Marcelo Perine, São Paulo, Loyola, 2002.

BOSCHI, C. C. "A Universidade de Coimbra e a formação intelectual das elites mineiras coloniais", Revista Estudos Históricos, 4/7 (1991), pp. 100-111.

CAMPOS, F. A. “Uma disputa escolástica no século XVIII. Documentário de filosofia no Brasil", Revista Brasileira de Filosofia, XVII (1967), pp. 203-208.

CERQUEIRA, L. A. Filosofia brasileira: a ontogênese da consciência de si, Petrópois, Vozes, 2002.

DOMINGUES, I. "Filosofia no/do Brasil: os últimos cinquenta anos", Revista Analytica, 17/2 (2013), pp. 75-104.

DUNS ESCOTO, J. Tratado do Primeiro Princípio, tradução do latim e nótula introdutória por Mário Santiago de Carvalho, Lisboa, Ed. 70, 1998.

DUNS SCOTUS, J. Collationes Parisiensis et Oxoniensis, en Opera Omnia II/1, a cura di Giovanni Lauriola, Italy, AGA, 1998. (Quaderno n. 12).

DUNS SCOTUS, J. Lectura, en Opera Omnia. II/1, a cura di Giovanni Lauriola, Italy, AGA, 1998. (Quaderno n. 12).

DUNS SCOTUS, J. Ordinatio, en Opera Omnia. III/1, a cura di Giovanni Lauriola, Italy, AGA, 2001. (Quaderno n. 16).

DUNS SCOTUS, J. Quaestiones Quodlibetales, en Opera Omnia XII. Hildesheim: G. O. Verlags, 1969.

DUNS SCOTUS, J. Quaestiones subtillissimae super libros Metaphysicorum Aristotelis, en Opera Omnia I, a cura de Giovanni Lauriola, Italy, AGA, 1998. (Quaderno n. 11).

DUNS SCOTUS, J. Quaestiones super librum Perihermeneias, en Opera Omnia I, a cura de Giovanni Lauriola, Italy, AGA, 1998. (Quaderno n. 11).

DUNS SCOTUS, J. Quaestiones super Praedicamenta, en Opera Omnia I, a cura de Giovanni Lauriola, Italy, AGA, 1998. (Quaderno n. 11).

DUNS SCOTUS, J. Reportata Parisiensia, en Opera Omnia II/2, a cura de Giovanni Lauriola, Italy, AGA, 1999. (Quaderno n. 14).

DUNS SCOTUS, J. Theoremata, en Opera Omnia I, a cura de Giovanni Lauriola, Italy, AGA, 1998. (Quaderno n. 11).

FARIA, F. Conclusiones Metaphysicas de Ente Reali, Flumine Januarii, Secunda Typographia Antonii Isidorii da Fonseca, 1747.

FRANCA, L. O método pedagógico dos Jesuítas - o "Ratio Studiorum", Rio de Janeiro, Agir, 1952.

LEITE, S. História da Companhia de Jesus no Brasil, tomo VII, Séculos XVII-XVIII, Rio de Janeiro, Instituto Nacional do Livro, 1949.

MARGUTTI, P. História da filosofia do Brasil (1500-hoje): $1^{a}$ parte: o período colonial (1500-1822), São Paulo, Loyola, 2013. 
MARQUES, L. A. Philosophia Brasiliensis: história, conhecimento e metafísica no período colonial, Porto Alegre, FI, 2015.

MORAES, R. B. Bibliographia Brasiliana. A bibliographical essay on rare books about Brazil published from 1504 to 1900 and works of Brazilian authors published abroad before the Independence of Brazil in 1822, volume I, Amsterdam - Rio de Janeiro, Colibris, 1958.

PIO XII. Index Librorum Prohibitorum, Vaticanae, Typis Polyglottis Vaticanis, 1940.

PRENTICE, R. P. The basic quidditative metaphysics of Duns Scotus as seen in his De primo principio, Roma, PAA, 1997.

TODISCO, O. Lo spirito cristiano della filosofia di Giovanni Duns Scoto, Roma, Abete, 1975.

VAZ, H. C. L. "O problema da filosofia no Brasil", Síntese - Revista de Filosofia, 30 (1984), pp. 11-25.

Endereço do Autor:

R. Azevedo Costa, 60

B. Boa Vista

38017-130 Uberaba - MG

marques.filos@yahoo.com.br 